\title{
PS Selection Method for and Application to GB-SAR Monitoring of Dam Deformation
}

\author{
Xia Xiang $\mathbb{D}^{1},{ }^{1}$ Jiankang Chen $\mathbb{D D}^{1},{ }^{1}$ Hui Wang $\mathbb{D}^{2},{ }^{2}$ Liang Pei, ${ }^{1}$ and Zhenyu Wu $\mathbb{D}^{1}$ \\ ${ }^{1}$ College of Water Resource \& Hydropower, State Laboratory of Hydraulic and Mountain River Engineering, Sichuan University, \\ Chengdu 610065, Sichuan Province, China \\ ${ }^{2}$ Sichuan Provincial Station of Surveying and Mapping Product Quality Supervision and Inspection, Chengdu 610065, \\ Sichuan Province, China \\ Correspondence should be addressed to Xia Xiang; xiangxia@scu.edu.cn
}

Received 26 December 2018; Revised 31 July 2019; Accepted 5 October 2019; Published 7 December 2019

Academic Editor: Emanuele Brunesi

Copyright (c) 2019 Xia Xiang et al. This is an open access article distributed under the Creative Commons Attribution License, which permits unrestricted use, distribution, and reproduction in any medium, provided the original work is properly cited.

\begin{abstract}
Ground-based synthetic aperture radar (GB-SAR) is a relatively new technique that can be used to monitor the deformation of large-volume targets, such as dams, slopes, and bridges. In this study, the permanent scatterer (PS) technique is used to address the issues encountered in the continuous monitoring of the external deformation of an arch-gravity dam in a hydraulic and hydropower engineering structure in Hubei, China; the technique includes large image data sizes, high accuracy requirements, a susceptibility of the monitoring data to atmospheric disturbances, complex phase unwrapping, and pronounced decoherence. Through an in-depth investigation of PS extraction methods, a combined PS selection (CPSS) method is proposed by fully taking advantage of the signal amplitude and phase information in the monitored scene. The principle and implementation of CPSS are primarily studied. In addition, preliminarily selected PS candidates are directly used to construct and update a triangular irregular network (TIN) to maintain the stability of the subsequent Delaunay TIN. To implement this method, a differential-phase standard-deviation threshold method is proposed to extract PSs that are highly spatially coherent and consistent. Finally, the proposed CPSS was applied to the safety monitoring of the dam. The monitoring results are compared with conventional inverted plumb line monitoring results, and the proposed CPSS is found to be effective and reliable.
\end{abstract}

\section{Introduction}

In the early twenty-first century, the Italian researchers Ferreti et al. proposed a permanent scatterer (PS) technique for satellite-borne synthetic aperture radar (SAR) systems [1-4] that is an SAR displacement monitoring data processing technique [5-7]. This technique extracts targets with a stable phase and extremely high backscattering capacity (i.e., PSs) from long-time-series radar data using a statistical filter, and by modelling and analysing, the PSs obtains various estimated parameters [7]. This technique can significantly reduce the effects of atmospheric phase delays [5] and provides an accurate and reliable approach to estimating the residual phase of landforms.

In the past decade, more research has been conducted on many aspects of the PS technique, from algorithm design to the implementation process, resulting in the rapid development of the PS technique for a variety of applications. A number of PS methods for satellite-borne SAR systems have been proposed [8-13]. With the extensive application of this technique in satellite-borne SAR systems, the PS technique has been started to be used to address certain key issues in ground-based SAR (GB-SAR) systems, e.g., the effects of temporal decoherence, atmospheric disturbances, and noise on the accurate determination of deformation [5, 14-20]. At first, GB-SAR systems were primarily used for monitoring various types of landslide masses. For example, Tarchi et al. used a GB-SAR system to monitor the stability of a rocky slope [21, 22]. In the period from 2003 to 2012, a number of researchers used the GB-SAR technique to monitor the safety of soil slopes, providing timely early warning and precautions for landslide disasters [23-27]. In the period from 2010 to 2013, Casagli et al., Luzi et al., and Intrieri et al. [28-31] introduced the GB-SAR technique to volcano monitoring and achieved excellent 
results. In addition to the monitoring of natural targets, in 1999, Tarchi took the lead in applying the GB-SAR technique to the monitoring of the external appearance of dams. Gradually, Alba et al. [32], Luzi et al. [33], Qiu et al. [17], and Huang et al. [18] used the GB-SAR technique to realize the high accuracy (can be up to $0.1 \mathrm{~mm}$ ), noncontact monitoring of the external appearance of various dams $[19,34]$. This technique has also been applied to the safety monitoring and provision of disaster warning for artificial facilities [14, 22, 25, 34-39] such as municipal engineering structures $[40,41]$ and river embankments [42-44]. There are consistent effects from atmospheric disturbances, temporal decoherence, phase wrapping, and noise in all the applications of the GB-SAR technique, severely restricting the accurate retrieval of high-accuracy deformation information and significantly limiting the advantages (high accuracy, high resolution, and flexible operation) of the GBSAR technique. Thus, it is necessary to make full use of the properties of PSs to search for a sufficient number of highly temporally and spatially coherent PS point targets and investigate PS extraction methods suitable for GB-SAR data to compensate for the effects of the temporal and spatial decoherence, atmospheric disturbances, and noise on the accurate retrieval of deformation information from GB-SAR data $[5,14-20]$ to achieve all-weather, high-accuracy (theoretically of the submillimetre order), and high-resolution displacement monitoring over a large area. Hence, effective PS extraction has become the key to the realization of the powerful role of PSs in the GB-SAR technique.

In 2011, Long et al. [45], for the first time, discussed the characteristics and shortcomings of four common PS extraction methods for satellite-borne SAR systems and designed an improved PS selection method for satelliteborne radar data. In 2012, Liu et al. [46] studied various PS extraction methods for satellite-borne SAR systems in more detail; these researchers combined several single extraction methods in either series or parallel for the extraction of PSs and achieved satisfactory results. In 2015, Zeng et al. [47] discussed the use of a combination of a coherence coefficient threshold method $\left(\gamma_{\mathrm{T}}\right)$ and phase information in the extraction of PSs and used this method to produce a digital elevation model (DEM) from satellite-borne radar data. It was not until 2016 that $\mathrm{Hu}$ et al. [48] studied the PS extraction method in GB-SAR on the basis of a satellite-borne SAR PS extraction method. These researchers improved the accuracy of the PS technique in the retrieval of deformation information by compensating for the repeat-pass error. However, this method only discussed the repeat-pass error compensation of repetitive placement equipment in the long-period repetitive monitoring mode and is not applicable to the continuous monitoring mode of a long time series. In 2016, Michele et al. [35] summarized and evaluated various PS extraction methods based on previous work. There are three main methods, namely, the $\gamma_{\mathrm{T}}$ method, the phase dispersion threshold $\left(T_{\mathrm{D}}\right)$ method, and the amplitude dispersion index threshold $\left(D_{\mathrm{AT}}\right)$ method. All of these methods only extract PS points by using a single feature of a certain aspect of the target, while considering the high coherence and radiation stability of PS points, which need to be further improved.
In this study, a CPSS method is proposed considering the characteristics of the safety monitoring of a type of hydraulic and hydropower engineering structure, dams, including large GB-SAR image data sizes, high accuracy requirements, a susceptibility of the monitoring data to atmospheric disturbances, complex phase unwrapping, and pronounced decoherence. The CPSS method is designed by organically combining the $\gamma_{\mathrm{T}}$ method, $D_{\mathrm{AT}}$ method, and differential-phase standard-deviation threshold method. The CPSS method fully uses the amplitude and phase information of the targets in the monitored scene, combined with temporal and spatial coherence and consistency, to extract targets that have high coherence and can maintain phase stability during the entire process of monitoring. Thus, suitable density and reliable quality PSs can be obtained using this method. This study focuses primarily on the following areas: (1) The principle and implementation of the CPSS method are discussed, and the interactive determination of the thresholds is analysed. (2) When implementing the method, the preliminarily selected PS candidates (PSCs) are directly used to construct and update a triangular irregular network (TIN) to ensure the stability of the subsequent Delaunay TIN. In addition, a differentialphase standard-deviation threshold method is proposed to extract highly spatially coherent and consistent PSs. (3) The proposed method was applied to the safety monitoring of a dam, and the monitoring results are compared with those the inverted plumb line monitoring method. The comparison demonstrates that the CPSS method is effective and reliable.

\section{Research Methods}

\subsection{Analysis of the Problems in Conventional PS Selection} Methods

(1) The $\gamma_{\mathrm{T}}$ method $[38,39]$ identifies and extracts PSs with $\gamma$ of each pixel as the criterion. The $\gamma$ of a certain pixel is estimated based on the complex number information of the nearby pixels within a window range that includes the pixel (e.g., a $m \times m$ window) using the following the equation:

$$
\gamma=\frac{\left|\sum_{i=1}^{m} \sum_{j=1}^{n} M(i, j) \cdot S^{*}(i, j)\right|}{\sqrt{\sum_{i=1}^{m} \sum_{j=1}^{n}|M(i, j)|^{2} \cdot \sum_{i=1}^{m} \sum_{j=1}^{n}\left|S^{*}(i, j)\right|^{2}}}
$$

where $M$ and $S$ are the sets of complex numbers of the master and slave images, respectively, and $*$ is the conjugate operator of the complex numbers. A suitable $\gamma_{\mathrm{T}}$ is set. A point with $\gamma$ greater than $\gamma_{\mathrm{T}}$ is a PS point.

This method has a simple principle and involves simple calculations. However, because $\gamma$ is calculated based on the size of the local moving window, the difficulty in this method lies in striking a balance between the window size and the effectiveness of the PS points. The determination of $\gamma_{\mathrm{T}}$ is also an issue worth careful consideration. If $\gamma_{\mathrm{T}}$ is set too high, certain true and effective PS points are not 
accurately extracted, resulting in a reduction in the effectiveness of the method. If $\gamma_{\mathrm{T}}$ is set too low, certain severely decoherent pixels near true and effective PS points are misidentified as PS points, resulting in a reduction in the reliability of extraction of the PS points. Therefore, PS points identified and extracted using the $\gamma_{\mathrm{T}}$ method alone are extremely easily affected by the parameters, fluctuate relatively significantly, and are not sufficiently robust.

(2) In the $T_{D}$ method $[38,39]$, the $D$ of each pixel $(i, j)$ is calculated:

$$
D_{\varphi}=\frac{\operatorname{std}\left[\varphi_{l}(i, j)\right]}{\operatorname{mean}\left[\varphi_{l}(i, j)\right]}, \quad l=1,2, \ldots, N .
$$

Then, a suitable $T_{\mathrm{D}}$ is set. $D_{\varphi}(i, j)$ corresponding to each pixel is compared with $T_{\mathrm{D}}$. If $D_{\varphi}(i, j) \leq T_{\mathrm{D}}$, the pixel $(i, j)$ is selected as a PS point. This method involves simple calculations and is unaffected by neighbourhood signals but selects PS points based only on phase information. Using the phase information of the GB-SAR data that have not been subjected to atmospheric phase correction and noise phase removal treatments to calculate $D$ results in a reduction in the reliability of the selected PS points. Additionally, the observed phase is a wrapped phase instead of a complete phase value and has no strict proportional relationship with the scattering coefficient of the target. Consequently, $D$ cannot truly reflect the scattering stability of the target, and the selected PS point does not meet the stability requirements.

(3) The $D_{\text {AT }}$ method $[38,39]$ uses the amplitude dispersion of the same pixel in the time series as the criterion for selecting the PS points and quantitatively represents the amplitude dispersion with $D_{\mathrm{A}}$. According to Ferreti et al.'s concept [2], the relationship between the phase standard deviation $\sigma_{\phi}$ and $D_{\mathrm{A}}$ is

$$
\sigma_{\phi} \approx \frac{\sigma_{\mathrm{A}}}{m_{\mathrm{A}}}=D_{\mathrm{A}}
$$

where $m_{\mathrm{A}}$ and $\sigma_{\mathrm{A}}$ are the mean and standard deviation of the amplitude, respectively. This equation demonstrates that $D_{\mathrm{A}}$ can be used to directly represent the stability of the coherent points and select PS points. Equation (3) (i.e., Ferreti et al.'s concept) holds true only if the signal-to-noise ratio (SNR) of the pixel is relatively high. Thus, this method can ensure that the selected PS points are stable to a certain extent only when applied to pixels with a high SNR that have been extracted in advance.

2.2. CPSS Method. From the above analysis, a single PS selection method can never consider both the stability and high coherence of pixels and is extremely easily affected by parameter selection. PSs selected using a single PS selection method lack robustness. In addition, a single PS selection method cannot ensure that a sufficient number of PSs are selected. In addition, during the long-term continuous monitoring process of GB-SAR, the sliding track of the equipment is fixed on a stable platform to eliminate the placement error of repetitive orbit and the spatial baseline caused by the change in the orbit position. Therefore, the long-term data can be processed accordingly after temporal differential interference. Hence, the CPSS method is proposed based on the characteristics of the continuous monitoring data generated by GB-SAR systems. This method is an improvement over the $\gamma_{\mathrm{T}}$ method and the $D_{\text {AT }}$ method in the algorithm process. A differential-phase standard-deviation threshold method is also proposed and combined with the $\gamma_{\mathrm{T}}$ method and the $D_{\text {AT }}$ method for identifying PSs. In the identification and extraction of the PSs, the CPSS differs from a simple combination of the aforementioned three methods in series or parallel. The CPSS method considers both the acquisition of pixels with a high SNR or even high-quality imagery and the amplitude and phase information of each pixel. Moreover, this method considers the temporal stability and spatial continuity and selects a suitable number of true PSs.

The basic principle of the CPSS method is described as follows. First, $\gamma$ is calculated using equation (1), which is used for interference processing. $\gamma_{\mathrm{T}}$ is then set to remove severely decoherent targets in the region (e.g., water and vegetation-covered areas). On this basis, the proportion of decoherent targets in the image is analysed; if the proportion of decoherent targets reaches a certain value, the whole image is treated as a low-quality image. After all the low-quality images are removed, the image preprocessing is completed. Highly coherent targets in quality images are obtained. Under the premise of high time coherence, according to the PS theory of Ferretti et al. [2], when $D_{\mathrm{A}}$ is low, the SNR is high, and $D_{\mathrm{A}}$ can be used to indirectly reflect the phase stability of each pixel. Subsequently, $D_{\mathrm{A}}$ of each highly coherent point is calculated using equation (3), and $D_{\mathrm{AT}}$ is set. Points with $D_{\mathrm{A}}$ smaller than $D_{\mathrm{AT}}$ are extracted; these points are referred to as PSCs. Thus, points with stable temporal scattering properties are obtained. Finally, a Delaunay TIN is constructed based on the PSCs. Based on the standard deviation threshold of the differential phase of each side of the TIN, spatially continuous PSs that are relatively insignificantly affected by atmospheric disturbances (i.e., PSs that are spatially consistent and stable) are selected.

To implement this method, calculations should be performed according to the following steps:

(1) Calculation of $\gamma$ : in the $(K-1)$ interference images, the $\gamma$ time series $\left(\gamma^{1}, \gamma^{2}, \ldots, \gamma^{k}\right)$ for each interference pixel is calculated based on equation (1).

(2) Extraction of highly coherent pixels: based on the following equation, the average $\gamma\left(\bar{\gamma}_{i, j}\right)$ of the pixel $(i, j)$ in the time series is calculated. Pixels with $\bar{\gamma}_{i, j}$ greater than the given $\gamma_{T}$ are determined: 


$$
\begin{aligned}
& \bar{\gamma}_{i, j}=\frac{1}{K} \sum_{k=1}^{K} \gamma_{i, j}^{k}, \\
& \bar{\gamma}_{i, j} \geq \gamma_{T} .
\end{aligned}
$$

$\gamma_{\mathrm{T}}$ is freely set using a man-machine interaction method. A suitable $\gamma_{\mathrm{T}}$ can be determined based on the image quality; generally, $\gamma_{\mathrm{T}}$ is set to $0.6-1.0$ [49]. Pixels with $\bar{\gamma}_{i, j}$ greater than $\gamma_{\mathrm{T}}$ are extracted as highly coherent pixels.

(3) Calculation of the absolute deviation $\Delta \gamma_{i, j}$ of $\gamma$ of each pixel: the $\gamma$ variation pattern of the GB-SAR image series is studied and statistically analysed. $\Delta \gamma_{i, j}$ of each pixel in each image is calculated:

$$
\Delta \gamma_{i, j}=\left|\gamma_{i, j}^{k}-\bar{\gamma}_{i, j}\right|
$$

(4) Evaluation and removal of low-quality images: the distribution of $\Delta \gamma_{i, j}$ of the pixels in each image is analysed. Based on the $\Delta \gamma_{i, j}$ distribution curve and the statistical results, a threshold $T$ is set. The proportion of pixels with $\Delta \gamma_{i, j} \geq T$ within all the pixels in the image is determined and used as a metric for evaluating the image quality. Images with an overly high proportion of pixels with $\Delta \gamma_{i, j} \geq T$ are removed. Thus, high-quality images with highly coherent pixels are obtained, and the preprocessing for the identification and selection of PSs is complete.

(5) Identification and selection of PSCs: based on equation (3), $D_{\mathrm{A}}$ of each pixel is calculated, and a reasonable $D_{\mathrm{AT}}$ is searched for and set in an interactive manner. According to Ferretti et al. [2], $D_{\mathrm{AT}}$ is generally set to $0.25-0.30$. If $D_{\mathrm{A}}$ of a pixel is lower than the given $D_{\mathrm{AT}}$, the pixel is considered a PSC point; otherwise, the pixel is a non-PSC point.

(6) Construction of a Delaunay TIN: a TIN is constructed by connecting adjacent PSC points that have been obtained according to certain network construction criteria to facilitate differential calculation of the spatial stability and consistency based on the interferometric phase.

(7) Calculation of the spatial differential interferometric phase value of each baseline of the TIN: for a baseline $\mathrm{PQ}$ with points $\mathrm{P}$ and $\mathrm{Q}$ at its two ends, the spatial differential interferometric phase value $\Delta \varphi_{\mathrm{p}, \mathrm{q}}$ is calculated as follows:

$$
\Delta \varphi_{\mathrm{p}, \mathrm{q}}=\varphi_{\mathrm{q}}-\varphi_{\mathrm{p}}
$$

where $\varphi_{\mathrm{p}}$ and $\varphi_{\mathrm{q}}$ are the interferometric phase values of the PSC points $\mathrm{P}$ and $\mathrm{Q}$, respectively, which can be determined based on the original interferometric values. $\Delta \varphi_{\mathrm{p}, \mathrm{q}}$ is calculated using equation (6). The absolute difference $\delta_{\mathrm{p}, \mathrm{q}}$ in the differential interferometric phase value between each baseline and the corresponding baseline in the adjacent time series is calculated:

$$
\delta_{\mathrm{p}, \mathrm{q}}=\left|\Delta \phi_{\mathrm{p}, \mathrm{q}}^{i+1}-\Delta \phi_{\mathrm{p}, \mathrm{q}}^{i}\right|, \quad i=1,2, \ldots, K-1 .
$$

The root-mean-square error (RMSE) of $\delta_{\mathrm{p}, \mathrm{q}}$ is also calculated and used to represent the extent of the change in the observed phase value of each baseline in the time series and indirectly reflect the extent to which the PSC points at the two ends of the baseline are affected by atmospheric disturbances.

(8) Selection of PSs using the threshold method: a threshold is set for the RMSE of the absolute difference in the spatial differential interferometric phase value. When the RMSE of the absolute difference in the spatial differential interferometric phase value of a baseline is lower than the threshold, the PSC points at the ends of the baseline are treated as the final PSs.

The above PS selection method has the following advantages:

(1) The $\gamma_{\mathrm{T}}$ method can rapidly eliminate highly decoherent non-PS targets in images and certain lowquality images, thereby reducing the search area for subsequent high-accuracy detection.

(2) The $D_{\mathrm{AT}}$ method is advantageous because this method can accurately identify single pixels and loses no resolution cells. The analyses of the $D_{\mathrm{AT}}$ method are based on the amplitudes of single pixels in the time series. Consequently, adjacent noisy PS pixels are unaffected by pixel noise in the spatial neighbourhood, and the $D_{\mathrm{AT}}$ method can independently detect PSs from noise bursts.

(3) Preliminary selection using the $\gamma_{\mathrm{T}}$ method and the $D_{\text {AT }}$ method before PS detection using the differential-phase RMSE threshold method results in a considerable decrease in the computational load of the whole process, prevents aimless global detection caused by a lack of preliminarily selected points for the differential-phase RMSE threshold method, results in a significant decrease in the computational time of the whole process, and can effectively improve the detection efficiency.

\section{Study Area and Research Data}

3.1. General Information on the Study Area. A case study is performed on the deformation monitoring of an archgravity dam in a hydropower station in Hubei, China. The top of the dam has an elevation of $206 \mathrm{~m}$ and a total length of $665.45 \mathrm{~m}$. The dam has a maximum height of $151 \mathrm{~m}$. Gravity dam segments are constructed on the two banks of the dam. A gravity block is placed on the foundation surface on the left dam abutment with an elevation of 120-138 m. The dam 
is a three-centred monocurved composite arch-gravity dam with an upper gravity segment, a lower arch segment, and an outer arc radius of $312 \mathrm{~m}$ that spans the riverbed. The top of the dam above the centre of the riverbed has an elevation of $181 \mathrm{~m}$ that gradually decreases towards the two banks. The left bank is $150 \mathrm{~m}$ away from the top of the gravity block, and the right bank is $160 \mathrm{~m}$ away from the top of the gravity block. A transition section is constructed to connect the left and right banks. The overflow section, situated in the centre of the dam, has seven surface outlets, four deep holes, and two relief outlets that double as diversion bottom outlets. The top of each surface outlet weir has an elevation of $181.8 \mathrm{~m}$, and each surface outlet has dimensions of $12 \mathrm{~m} \times 18.2 \mathrm{~m}$. The bottom of each deep hole has an elevation of $134 \mathrm{~m}$, and each deep hole has dimensions of $4.5 \mathrm{~m} \times 6.5 \mathrm{~m}$. The bottom of each bottom outlet has an elevation of $95 \mathrm{~m}$, and each bottom outlet has dimensions of $4.5 \mathrm{~m} \times 6.5 \mathrm{~m}$. Each outlet/hole is controlled by an arcshaped sluice gate. The powerhouse is situated on the river terrace by the right bank. There is a $300 \mathrm{t}$ class vertical ship lift on the left bank, and the middle ship diversion canal is $400 \mathrm{~m}$ in length and $30 \mathrm{~m}$ in width.

3.2. Research Data. In this paper, the GB-SAR IBIS-L system developed by Italian IDS company and the University of Florence was used for continuous monitoring of the dam. The step frequency continuous wave (SFCW) was adopted to realize high-precision static displacement monitoring, and the average sampling frequency is $110 \mathrm{~Hz}$; this system is different from the GB NW-SAR system of Lukin et al. $[50,51]$, but the monitoring accuracy can reach the submillimeter level. A total of 1,330 images of the dam area were collected. During the data collection process, the IBIS-L system was placed on the left bank $1,300 \mathrm{~m}$ downstream of the dam, and the field of view completely of the system covered the dam and the slopes on the two banks, the ship lift on the left bank, and the ship diversion canal in the downstream riverbed. Figure 1 shows the relative locations of the IBIS-L system and the targets monitored in the field. The lower left corner of Figure 1 shows the corresponding locations of the buildings and structures in a GB-SAR image (A: dam, B: power station by the right bank and slope steps, C: ship diversion canal in the riverbed, and D: two-level ship lift on the left bank).

Monitoring was performed for seven days (approximately $147 \mathrm{~h}$ ), and images of 1,330 scenes were collected. Table 1 summarizes the basic parameter settings for data collection.

Considering the relatively large data size, only the data processing for the main body of the dam is presented in this article. Figure 2 shows the main body of the dam.

\subsection{Data Processing}

3.3.1. Data Processing Procedure. The data collection process coincided with the flood season with relatively high precipitation that resulted in accumulated water on the downstream riverbed. As a result, the observation data were significantly affected by temporal decoherence and atmospheric disturbances. To effectively eliminate these effects, a long-time-series image postprocessing method based on the PS technique was employed to process the images of 1,330 scenes. The CPSS method was proposed to achieve accurate calculation of the deformation information. First, based on the actual temporal and spatial correlations between the images, low-quality images (of 385 scenes) were eliminated, and the images of the remaining scenes were analysed and processed. The processing procedure included original image focusing, master image selection, interferometric image generation, phase unwrapping, PS point selection, PS TIN construction, PS network modelling, and least squares adjustment. The rate, amount, and trend of the deformation of the dam during the monitoring period were thereby determined. The results were compared with the observed values obtained using the conventional inverted plumb line method to verify the effectiveness of the combined PS point selection method for the monitoring of the external deformation of the dam. Figure 3 shows the processing procedure.

3.3.2. Extraction of PS Points. A total of 945 interferometric images of the dam area expressed in a rectangular plane coordinate system were obtained after the preprocessing process, which included interferometric image generation and low-quality image removal. Figure 4 shows one of the interferometric images. In the figure, the $x$-axis represents the direction along the dam axis, and the $y$-axis represents the distance between the IBIS-L and the dam. The dam, a concrete and metal structure, reflected the microwave signals extremely strongly, resulting in the formation of very strong echo signals. The deformation of the dam can be effectively interpreted by taking full advantage of the radiation and phase information derived from the time-series images. In this study, PS points were extracted using the $\gamma_{\mathrm{T}}$ method, the $T_{\mathrm{D}}$ method, the $D_{\mathrm{AT}}$ method, and the proposed CPSS method to comparatively analyse the deficiencies and advantages of these methods.

First, the $\gamma_{\mathrm{T}}$ method was used to calculate and statistically analyse all the image data. The window size and threshold were set to $5 \times 5$ and 0.8 , respectively. Figure 5 shows the extracted PS points (in black). There were a total of 8,623 PS points, accounting for $37.5 \%$ of all the pixels. The radar images were upside down, so the surface outlets of the dam were located at the top of the images. The metal gates and other metal components of the surface outlets had very high scattering capacities. However, when selecting stable points, only the temporal correlation of the image was considered, and the phase stability was not considered. As a result, a large number of points on the image were mistakenly selected as PS points.

When using the $D_{\mathrm{AT}}$ method, the amplitude dispersion cannot accurately represent the phase stability of the pixels when there are too few images or when the images are of relatively low quality, and consequently, certain points with a stable phase are omitted. $D_{\mathrm{AT}}$ was set to 0.3 . A total of 4,497 PS points were obtained, accounting for $19.56 \%$ of all the 

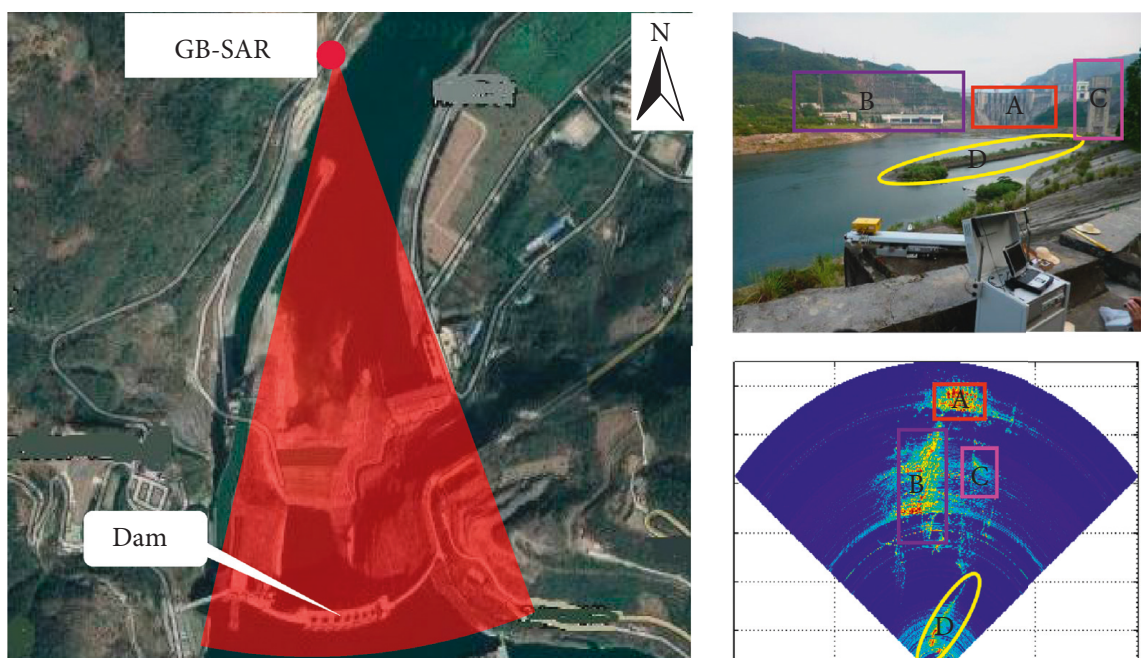

Figure 1: GB-SAR monitoring equipment layout diagram. The lower left corner shows the corresponding locations of the buildings and structures in a GB-SAR image.

TABLE 1: Basic information of dam deformation monitoring data collection.

\begin{tabular}{lcr}
\hline Antenna type & Gain & \multicolumn{2}{c}{$20 \mathrm{dBi}$} \\
VV & Polarization mode & $\mathrm{Ku} / 1.78 \mathrm{~cm}$ \\
Signal type & Frequency band and wavelength & Bandwidth \\
& Step frequency & $300 \mathrm{M}(17.05 \mathrm{GHz}-17.35 \mathrm{GHz})$ \\
\hline Synthetic aperture length & $57.703 \mathrm{kHz}$ & $2 \mathrm{~m}$ \\
\hline In-orbit moving step of the sensor & Range & $5 \mathrm{~mm}$ \\
\hline Resolution & Azimuth & $0.5 \mathrm{~m}$ \\
\hline Maximum monitoring distance setting & & $4.4 \mathrm{mrad}$ \\
\hline Average duration of collection of a single-scene image & & $1300 \mathrm{~m}$ \\
\hline
\end{tabular}

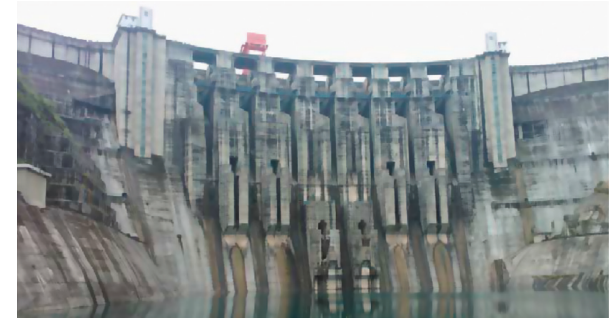

Figure 2: Photograph of the main body of the dam.

pixels, as shown in Figure 6. By interactively setting $D_{\mathrm{AT}}$, when the given $D_{\mathrm{AT}}$ was strict, e.g., when $D_{\mathrm{AT}}$ was set to 0.25 , the number of obtained PS points significantly decreased to 3,252 . Based on the physical meaning of $D_{\mathrm{A}}$, the lower $D_{\mathrm{AT}}$ is, the more reliable the selected PS points are. However, a small $D_{\text {AT }}$ cannot ensure a sufficient number of PS points. Thus, to ensure that a sufficient number of PS points could be selected, $D_{\text {AT }}$ was set to 0.3 .

Figure 7 shows the result obtained by calculation based on the statistics of the image phase stability using the $T_{D}$ method. The average phase dispersion in the image was 73.3149, which is very high. To obtain relatively reliable PS points, $T_{\mathrm{D}}$ was set to 4 . Under this condition, only 5,342 PS points were obtained, accounting for $23.2 \%$ of all the pixels. Despite this result, as shown in Figure 8, the extracted PS points were not stable points in a true sense. Many of these points had very low scattering strengths. Additionally, the selected points were basically evenly distributed throughout the whole image. The effects of the scattering strengths of the targets were not considered. Both the objects monitored and the surrounding backgrounds were treated as stable PS points. The stability and high scattering capacity of the points could not be correctly reflected at all, and the main area of the body could not be identified. By relaxing the threshold range, an even larger number of false PS points distributed in a more disorderly manner would be obtained, which would completely conceal the true characteristics of the objects. Therefore, the reliability of the wrapping and severely atmospherically disturbed phase information significantly decreased when obtaining reliable PS points.

Finally, the CPSS method was employed to extract the PS points. During the extraction process, an image quality threshold was set by statistically analysing the deviation of $\gamma$ of each pixel in the interferometric image of each scene, and lowquality images were removed. PS points were extracted only from images of relatively high quality. The statistical results show that the absolute deviations of the values of $\gamma$ were 


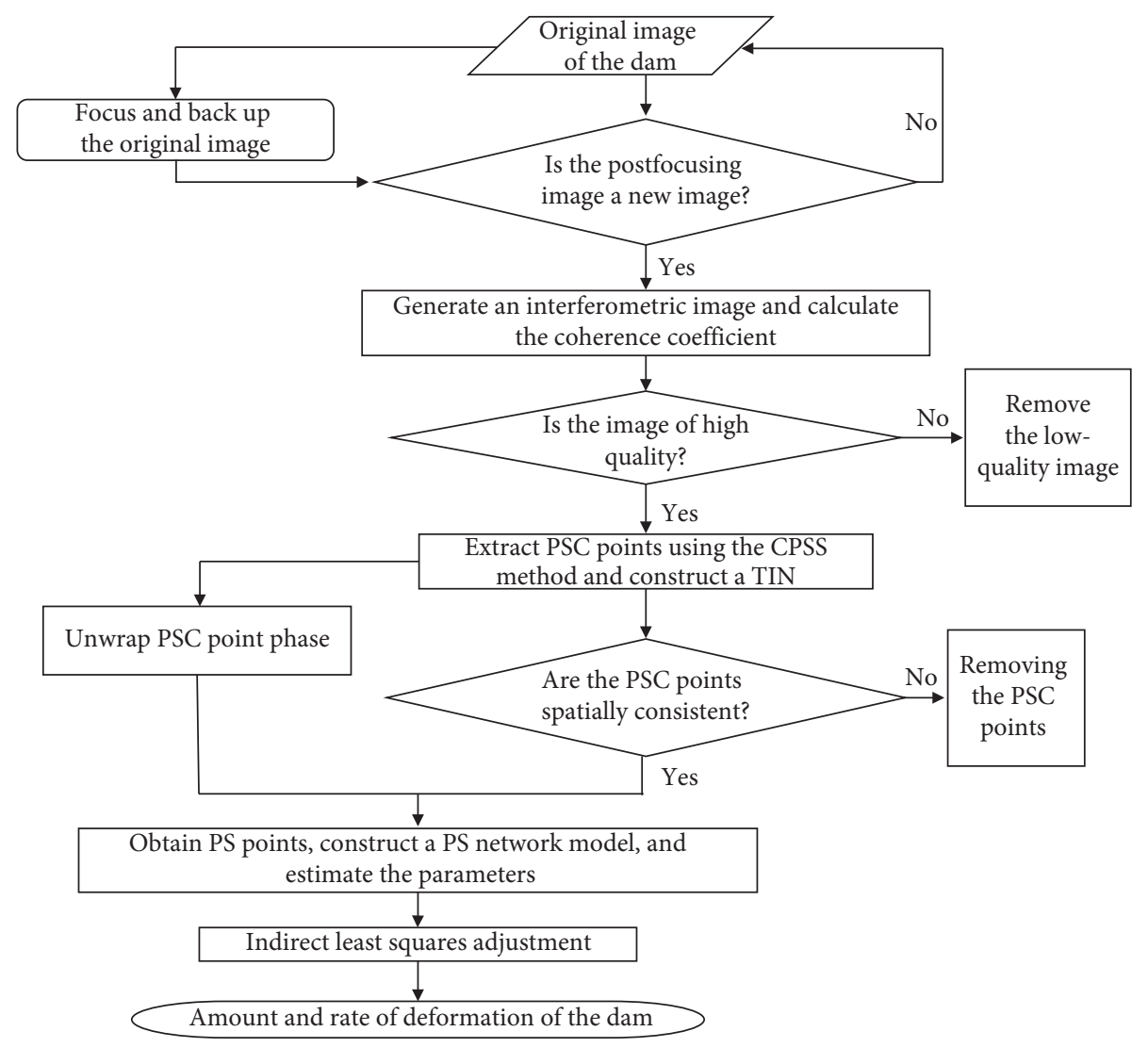

FIGURE 3: Research roadmap for using the CPSS method to select PS points for deformation monitoring of a dam.

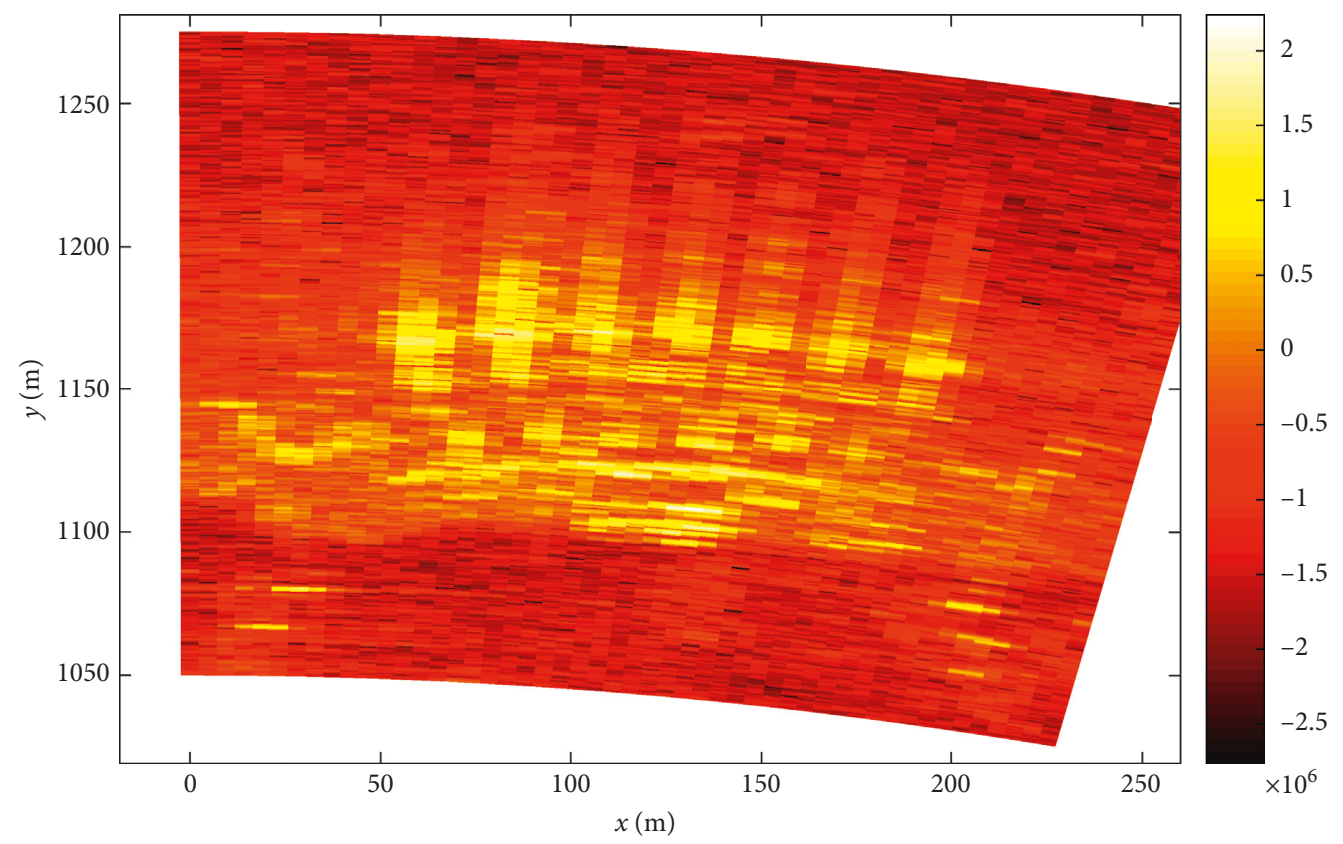

FIGURE 4: Interferometric image of the main body of the dam area (interferometric result of 1st and 2nd scene images, the $x$-axis represents the direction along the dam axis, and the $y$-axis represents the distance between IBIS-L and the dam).

mostly below 0.15 , suggesting relatively high accuracy, as shown in the histogram in Figure 9. Thus, when determining the low-quality image threshold, images with more than $20 \%$ of the pixels with an absolute deviation of $\gamma$ greater than 0.15 were considered low-quality images and removed. Ultimately, of all the images of the whole time series, a total of 385 lowquality images were removed, and the remaining 945 images were subjected to subsequent processing analysis. 


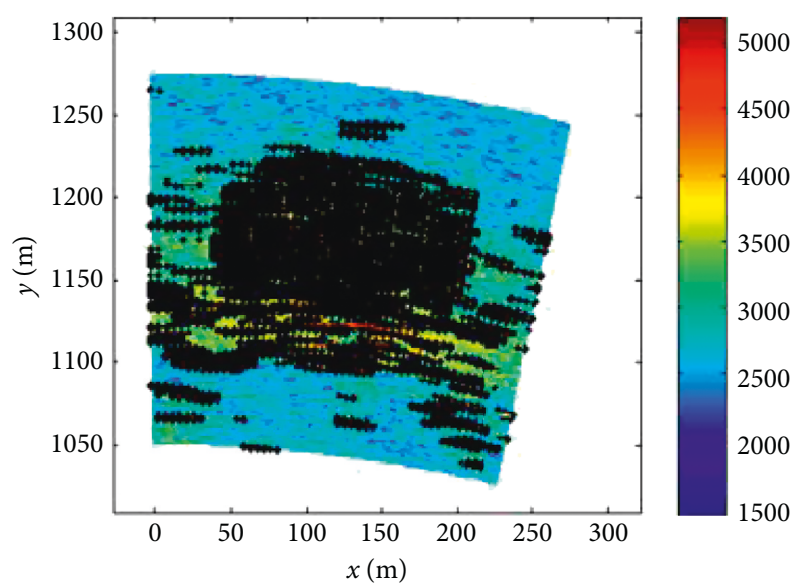

FIGURE 5: PS points extracted using the correlation coefficient threshold method (the black dots are PSs).

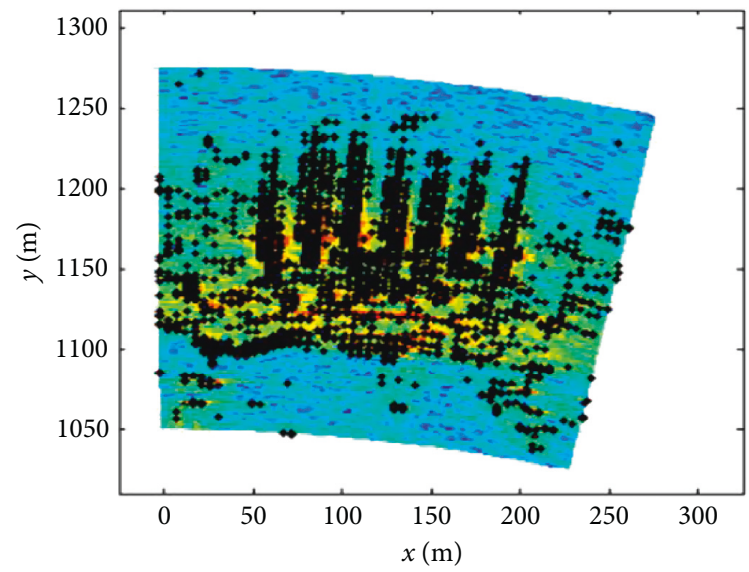

FIGURE 6: PS points extracted using the $D_{\mathrm{AT}}$ method (the black dots are PSs).

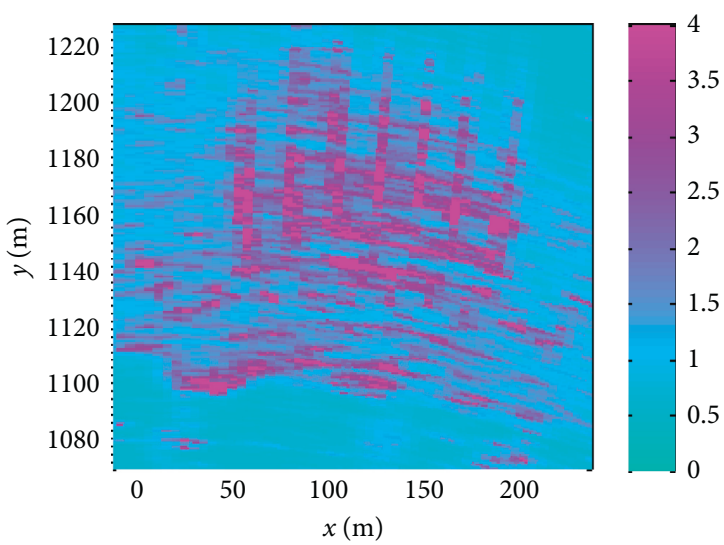

Figure 7: Distribution of phase stability of the dam.

PS points were preliminarily extracted from the $945 \mathrm{im}$ ages with relatively high quality using the $\gamma_{\mathrm{T}}$ method. To ensure that as many highly coherent points as possible could be extracted from the images, the size of the moving calculation window was still set to $5 \times 5$, and the average $\gamma_{\mathrm{T}}$ was 0.8 .

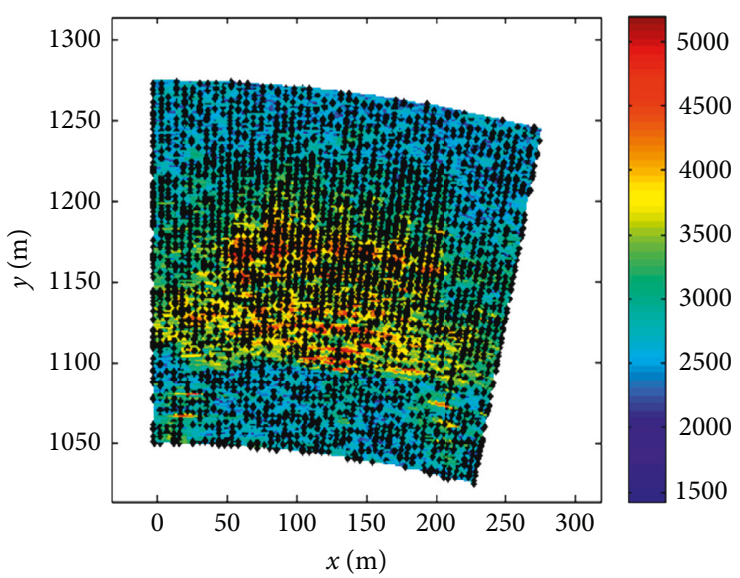

Figure 8: PS points selected using the $T_{\mathrm{D}}$ method (the black dots are PSs).

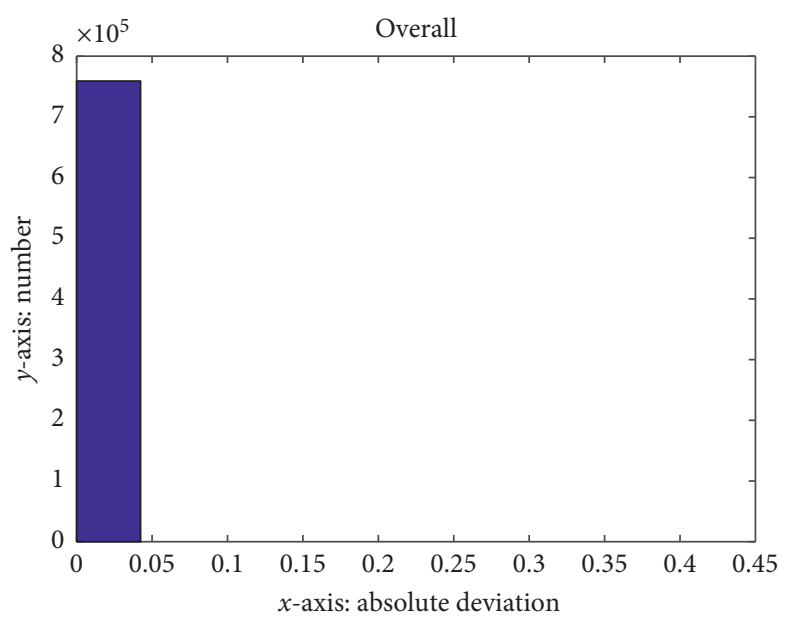

Figure 9: Histogram of distribution of the absolute deviations of the $\gamma$ values.

A total of 8,623 highly coherent points were thus obtained. Subsequently, the phase information on the preliminarily selected highly coherent points was further considered. Because there were sufficient images, it was feasible to use the relatively high-performance $D_{\mathrm{AT}}$ method to further select PSC points. To facilitate comparison with the aforementioned results obtained using the $D_{\mathrm{AT}}$ method alone, $D_{\mathrm{AT}}$ was again set to 0.3 , and a total of 5,817 PSC points were obtained. The removal of the low-quality images resulted in significant improvement in the reliability of the $D_{\mathrm{AT}}$ method. This result demonstrates the characteristics of $D_{\mathrm{A}}$ : an image of relatively high quality has a relatively high SNR, and $D_{\mathrm{A}}$ of the image is approximately equal to the phase standard deviation. Thus, the phase information of the image is indirectly considered by means of $D_{\mathrm{A}}$, and consequently, reliable PSC points can be obtained. Subsequently, a Delaunay TIN was constructed based on the PSC points. Figure 10 shows the preliminary TIN.

The spatial continuity of each PSC point in the TIN was examined. The RMSE of the absolute difference in the differential interferometric phase value of each baseline of the network was calculated. Points that were spatially 
discontinuous or significantly affected by atmospheric disturbances were removed. The absolute differences in the differential interferometric phase values were calculated and statistically analysed. The maximum, minimum, and average RMSEs were 3.3035, 0.0074, and 1.2078, respectively. The average RMSE of 1.2078 was selected as the threshold, and PSC points with an RMSE greater than the threshold were removed. A total of 4,289 PS points were ultimately obtained, accounting for $18.65 \%$ of all the points. Figure 11 shows the results of the CPSS method. The PS points in each image were subjected to temporal and spatial phase wrapping, and a PS TIN was reconstructed (Figure 12). A total of 14,433 baselines and 9,617 triangles were obtained.

\subsubsection{Analysis of the Amount and Rate of Deformation of the} Dam. Based on the relationship between the observed differential phase value of each baseline in the PS network and the amount of deformation, spatially, the observed differential phase value of each baseline was mathematically modelled, and the parameters were estimated. Finally, through the indirect adjustment of the PS network, the deformation information of the dam during the monitoring period was obtained. Figure 13 shows the total amount of deformation at each PS point during the whole monitoring period obtained through direct adjustment. The amounts of deformation were generally approximately $5 \mathrm{~mm}$, and all the PS points shifted downstream. The monitoring process was continuous and conducted in the height of the summer. During this time, the meteorological conditions in the dam area underwent complex changes. Two heavy thunderstorm events occurred during the monitoring process. These environmental factors still systematically affected the PS processing results. Therefore, two control points, GCP1 and GCP2, were selected on the banks of the dam to correct the changes in the environmental quantities. The two control points were located at $(5.0,1,144.7)$ and $(219.7,1,121.9)$ in the image coordinate system. Table 2 summarizes the signal strengths and phase stabilities at these two points.

Figure 14 shows the total amount of deformation at each PS point during the monitoring period after the correction of the environmental quantities. The corrected results show that the deformation at the majority of the PS points was $-1.0-1.0 \mathrm{~mm}$. The deformation at the arch crown was the largest, with the cumulative deformation value of $1.61 \mathrm{~mm}$. The horizontal displacement of the dam body shows a trend of gradual decrease from the arch crown to both sides. Figure 15 shows the average rate of deformation at each PS point on the dam during the monitoring period, which ranged from -0.1140 to $0.0980 \mathrm{~mm} / \mathrm{d}$. The dam deformed slowly and was in a stable operating condition.

\section{Analysis of Results and Discussion}

To examine the reliability of the CPSS method for the visual monitoring of the dam, the monitoring results were compared with inverted plumb line monitoring results. The five points, P1 P5, of the intersection between five inverted plumb lines evenly distributed across the dam and the top of

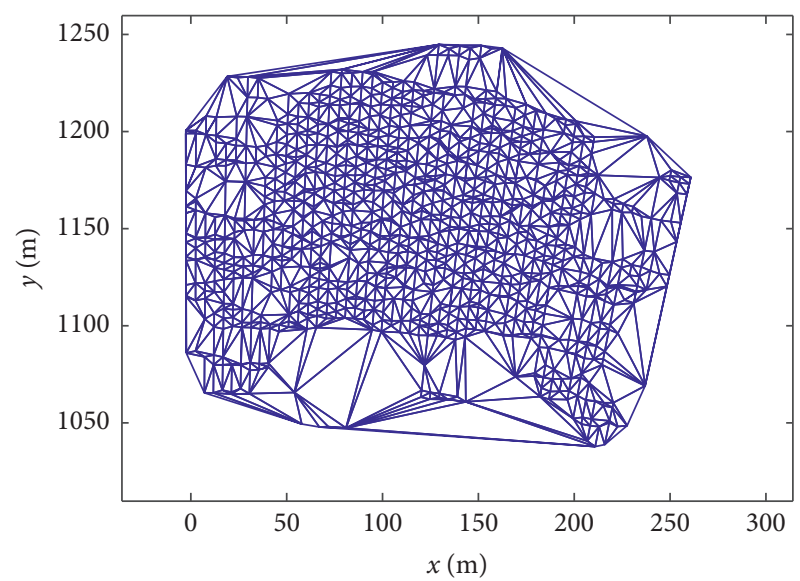

FIgUre 10: Delaunay TIN constructed based on the PSC points.

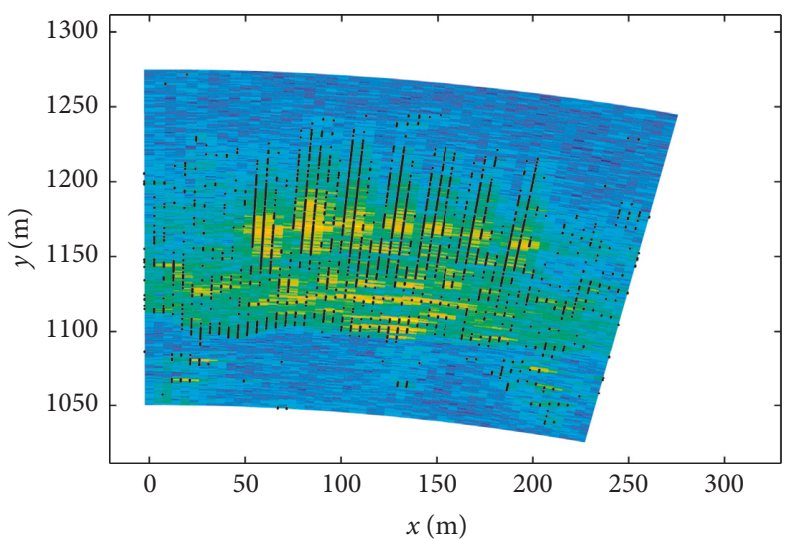

FIGURE 11: PS points extracted using the CPSS method (the black dots are PSs).

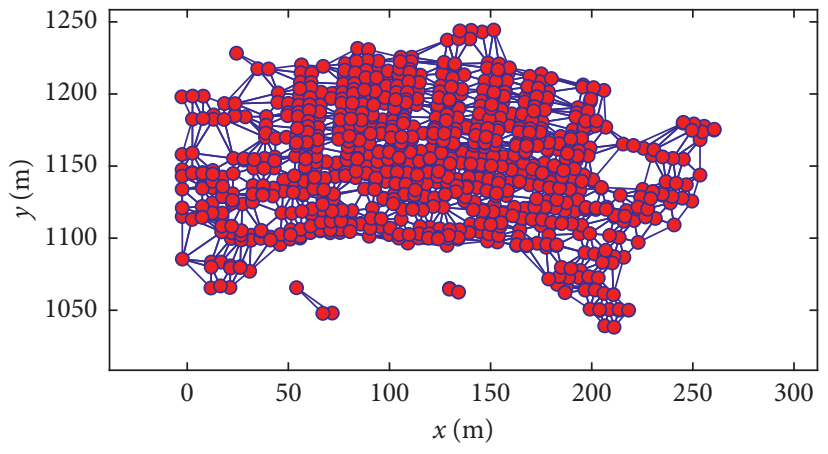

FIGURE 12: Ultimate spatially continuous PS Delaunay TIN.

the dam were selected as the objects of comparison. Figure 16 shows the distribution of the five points (the red points) located in the GB-SAR monitoring images. The deformation information obtained using the two methods was analysed.

The radar images are upside down. Thus, on the same vertical plane in an image of the dam, the lower the height of a target is, the further away the target is from the origin of the 


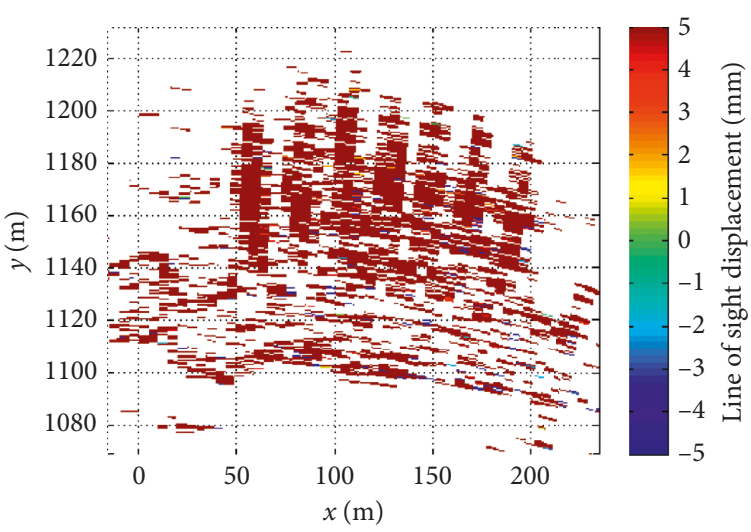

FIGURE 13: Nonenvironmentally corrected amounts of deformation (the shade of color represents the magnitude and direction of the displacement).

TABLE 2: Information on the environmental correction control points.

\begin{tabular}{lcccccc}
\hline Point & $X(\mathrm{~m})$ & $Y(\mathrm{~m})$ & Thermal SNR & Estimated SNR & $\gamma$ & Phase stability \\
\hline GCP1 & 5.0 & 1144.7 & 36.2 & 33.9 & 0.97 & 15.86 \\
GCP2 & 219.7 & 1121.9 & 31.3 & 23.4 & 0.97 & 4.28 \\
\hline
\end{tabular}

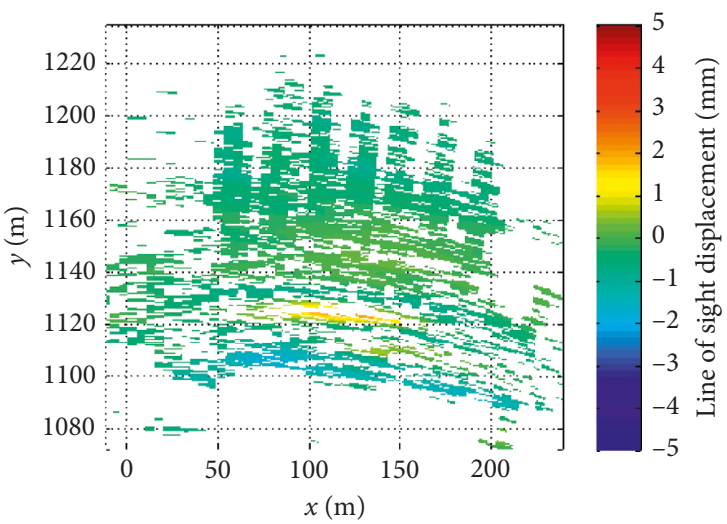

FIGURE 14: Environmentally corrected amounts of deformation (the shade of color represents the magnitude and direction of the displacement).

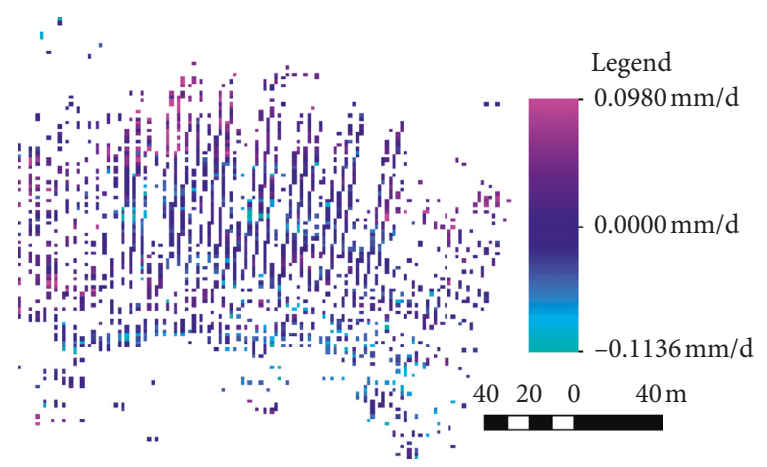

Figure 15: Average rate of deformation at each PS point $(\mathrm{mm} / \mathrm{d}$, the shade of color represents the magnitude of the rate of displacement). radar coordinate system; conversely, the greater the height of a target is, the closer the target is to the origin of the radar coordinate system. In Figure 17, the black curve signifies the top of the dam, and the part above the black curve is the image of the seven surface outlets. Due to the presence of metal equipment in the surface outlets, the outlets strongly reflected the signals, forming high-quality echo signals. Figure 18 shows the corresponding locations of points P1 P5 in a radar image. Table 3 summarizes the coordinates of the five points in the image. Figures 19 and 20 show the temporal and spatial deformation distribution curves of the five points on the top of the dam for the monitoring period obtained based on the GB-SAR and inverted plumb line automatic monitoring results. Table 4 shows the corresponding characteristic deformation values. Figure 21 shows the spatial distributions of the amounts of deformation of the five points on the top of the dam.

Figures 19 and 20 and Table 4 show that from July 27 to August 2, the amounts of deformation of the GB-SAR measuring points were generally small; the deformation of P3 was the largest at approximately $1.5 \mathrm{~mm}$ downstream. The deformations of the inverted plumb line measuring points $\mathrm{P} 1 \sim \mathrm{P} 5$ are relatively small, with $\mathrm{P} 3$ being the largest at $1 \mathrm{~mm}$ downstream. The trends of the two methods are consistent, and the amounts of deformation measured differ by approximately $0.5 \mathrm{~mm}$ mainly due to the difference between the two monitoring methods in the starting data; that is, the GB-SAR measurement value is the displacement relative to the centre of the equipment, while the inverted plumb line measurement value is the displacement relative to the inverted steel wire. Moreover, if the line-of-sight displacements measured by the GB-SAR system are transformed into the plane coordinate system for the test area, the displacement evaluation metrics are consistent, which leads to higher data comparability. This result demonstrates that 


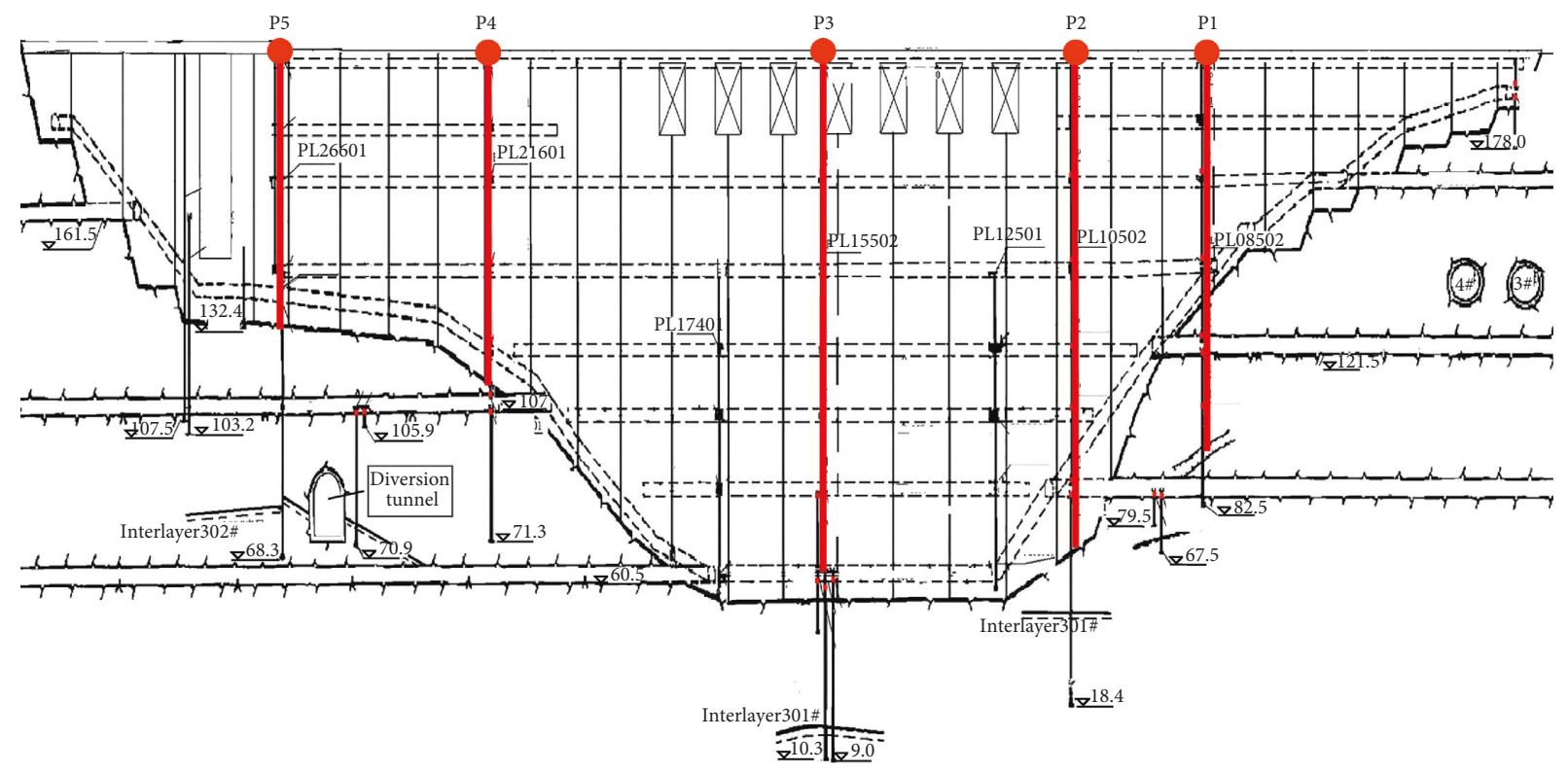

FIGURE 16: Distribution of inverted plumb line points at the top of the dam (the red dot indicates the inverted point of the dam crest).

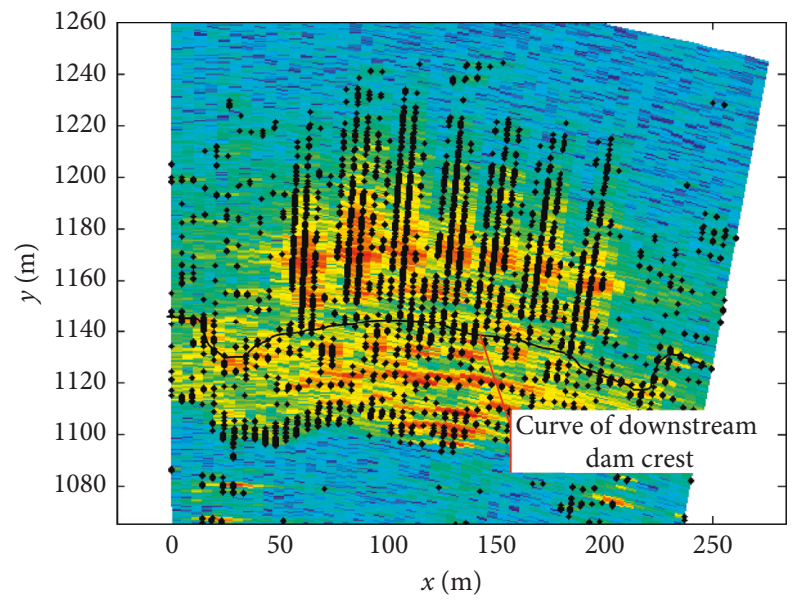

Figure 17: Contour curve of the top of the dam.

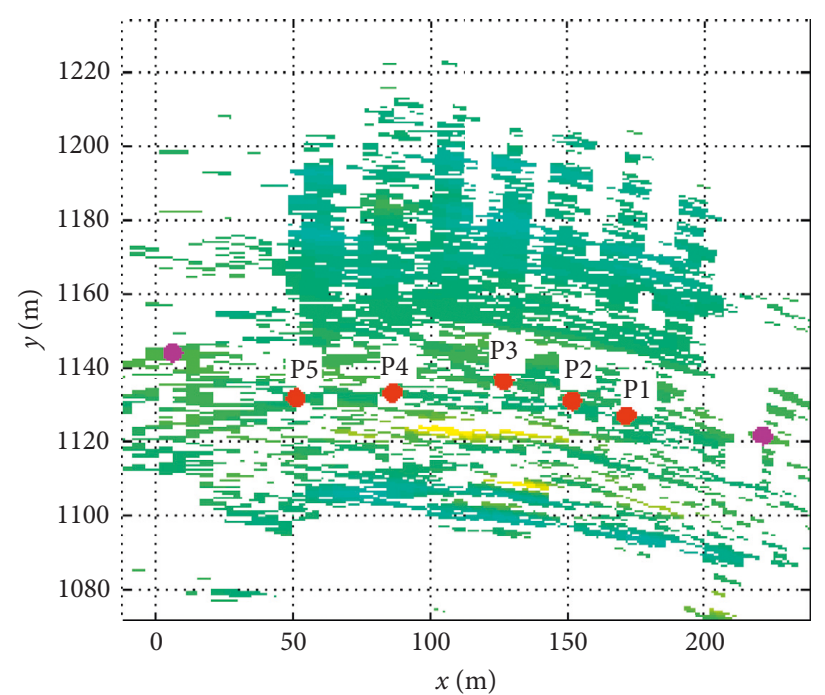

FIGURE 18: Distribution of the five points at the top of the dam in a GB-SAR image. 
TABLE 3: Coordinates of the five points at the top of the dam in the image coordinate system.

\begin{tabular}{lccccc}
\hline Point & P1 & P2 & P3 & P4 & P5 \\
\hline$X(\mathrm{~m})$ & 169.8 & 150.1 & 125.4 & 84.9 & 49.8 \\
$Y(\mathrm{~m})$ & 1127.5 & 1131.3 & 1136.8 & 1133.6 & 1132.1 \\
\hline
\end{tabular}

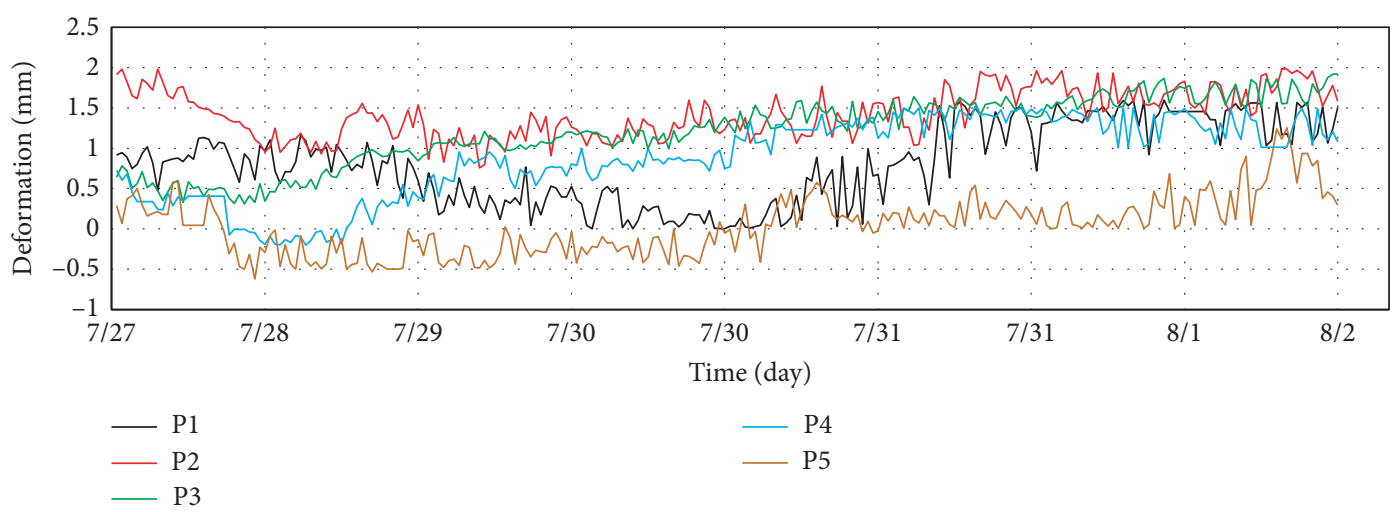

Figure 19: Temporal process curves of the five points at the top of the dam obtained using the PS method.

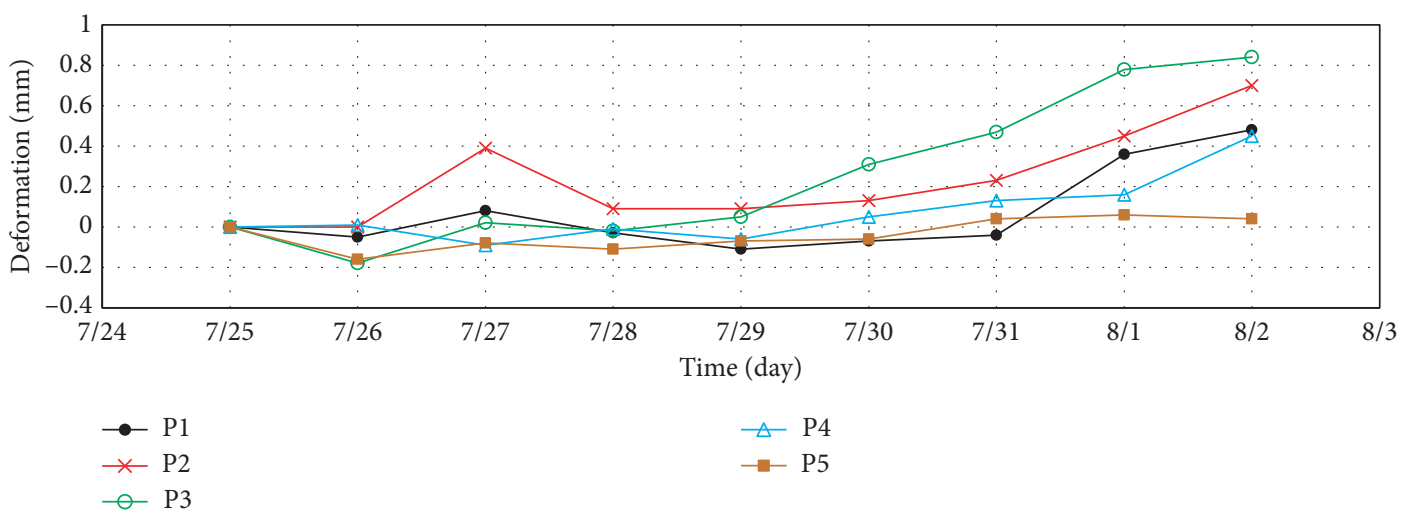

FIgURE 20: Temporal process curves at the five points at the top of the dam obtained using the inverted plumb line method.

TABLE 4: GB-SAR/inverted observation point deformation characteristic value statistics of dam crest.

\begin{tabular}{lcccccc}
\hline \multirow{2}{*}{$\begin{array}{l}\text { GB-SAR (inverted plumb } \\
\text { points) }\end{array}$} & \multicolumn{2}{c}{ GB-SAR measurements $(\mathrm{mm})$} & \multicolumn{3}{c}{ Inverted plumb line measurements (mm) } \\
& Maximum & Minimum & Cumulative & Maximum & Minimum & Cumulative \\
value & value & value & value & value & value \\
\hline P1 & 1.49 & 0.12 & 1.37 & 0.48 & -0.11 & 0.59 \\
P2 & 1.98 & 0.76 & 1.22 & 0.70 & 0.09 & 0.61 \\
P3 & 1.91 & 0.31 & 1.61 & 0.84 & -0.02 & 0.86 \\
P4 & 1.32 & -0.19 & 1.51 & 0.45 & -0.09 & 0.54 \\
P5 & 1.05 & -0.53 & 1.58 & 0.06 & -0.11 & 0.16 \\
\hline
\end{tabular}

the combined PS point selection method can correctly reflect the deformation of a dam and effectively address the key problems in GB-SAR monitoring data processing (e.g., decoherence, phase unwrapping, and atmospheric phase correction), thereby allowing effective and reliable application of the GB-SAR technique to monitoring the visual deformation of dams.

As shown in Figure 21, the deformations of the measuring points by the inverted plumb line P1 P5 are $0.04 \mathrm{~mm} \sim 0.84 \mathrm{~mm}$, and the deformations of the measuring points by GB-SAR are $0.05 \mathrm{~mm} \sim 0.96 \mathrm{~mm}$; both methods show the largest deformation at the arch crown and downstream deformation, which is consistent with the deformation characteristics of an arch dam, and the deformation of the dam is stable.

According to the statistical analysis of the GB-SAR monitoring data, the errors in the deformation rates of the five characteristic points on the dam crest (see Table 5) are all smaller than $0.005 \mathrm{~mm} / \mathrm{d}$, indicating high monitoring accuracy. 


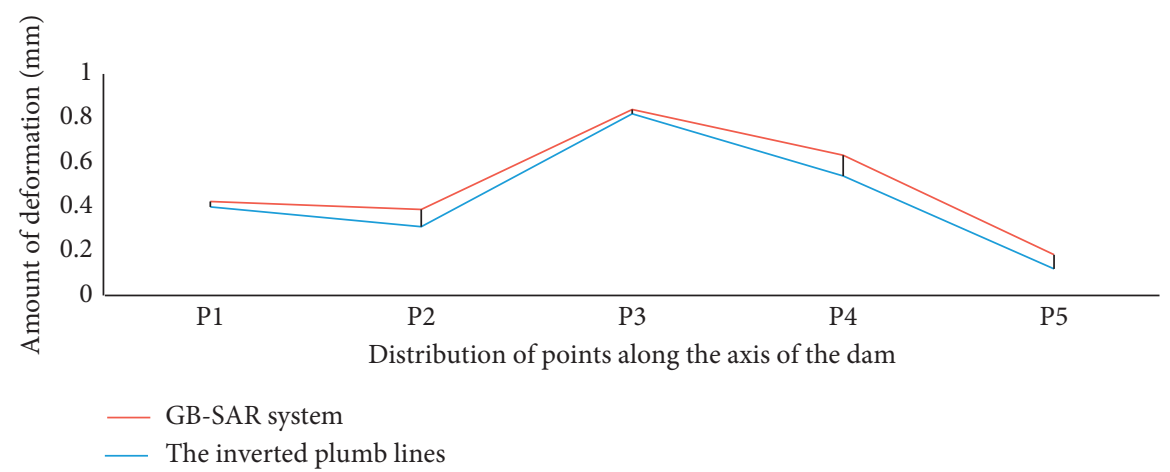

FIgURE 21: Spatial distribution of the amount of deformation of the top of the dam.

TABLE 5: GB-SAR deformation rate error statistics.

\begin{tabular}{lccccc}
\hline Measuring point & P1 & P2 & P3 & P4 & P5 \\
\hline RMSE of GB-SAR (mm/d) & 0.003 & 0.003 & 0.003 & 0.002 & 0.002 \\
\hline
\end{tabular}

\section{Conclusions and Suggestions}

A new method (i.e., CPSS) for identifying and extracting PSs is proposed considering the characteristics of GB-SAR data processing, including large image data sizes, high accuracy requirements, a high susceptibility of the monitoring data to atmospheric disturbances, complex phase unwrapping, and pronounced decoherence. The principle and implementation of the proposed method are investigated in detail. This method was applied to the safety monitoring of an archgravity dam in a hydraulic and hydropower engineering structure in Hubei, China. By comparing the results obtained using the combined method with inverted plumb line monitoring data, the effectiveness and reliability of the combined method are analysed. The contents and conclusions of this study are summarized as follows:

(1) The principle, implementation, and specific steps of the CPSS method were investigated in detail.

(2) In the implementation of the method, an absolute differential-phase difference threshold method was proposed by constructing a PSC TIN in advance and using the spatial coherence and consistency to extract spatially consistent and highly stable PSs from the TIN, thereby somewhat removing PSCs that are significantly affected by atmospheric disturbances.

(3) The difference between the CPSS method and the conventional single PS selection method was analysed. Additionally, the advantages of the CPSS method were discussed based on the data measured.

(4) The CPSS method was applied to monitoring images of an arch-gravity dam in Hubei, China, that were obtained continuously for seven days. A total of 1,330 images were processed and analysed, and PS targets that were highly coherent and had a stable phase were selected.

(5) The PS targets were processed to prevent errors due to temporal and spatial decoherence, phase unwrapping, and atmospheric disturbances. The total amount and daily average rate of deformation of the main body of the dam were determined. The results were compared with monitoring data measured using the conventional inverted plumb line method. The results show that the temporal and spatial deformation trends at various points at the top of the dam during the monitoring period agreed relatively well with the inverted plumb line results. The deformation at each characteristic point at the top of the dam was stable.

(6) The results for the entire dam demonstrated that the selected PS points met the requirements for analysing the deformation of the dam in terms of density and distribution and could be effectively substituted for the dam. In addition, the retrieval results demonstrate that the dam was in a stable condition and underwent insignificant deformation. The effects of changes in the water level in the upstream reservoir on the main fluctuations in the deformation of the dam should be considered.

The use of the PS technique in GB-SAR data processing ensures the application of the GB-SAR monitoring technique and has extensive application prospects in the high-accuracy, noncontact, all-weather, and automated safety monitoring of large-volume objects (e.g., dams, slopes, bridges, and landslide masses). However, the reliability and effectiveness of the identification and selection of PSs directly affect the monitoring accuracy. The new PS selection method provides a new approach for the high-accuracy, all-weather, and automated monitoring of the visual deformation of dams and slopes. Future research can be conducted in the following areas [52]:

(1) The flexibility and robustness of the PS selection method can be further improved to allow this method to be suitable for various types of monitoring models and data quality

(2) When the PS method is used, the examination of the phase unwrapping quality can be enhanced to prevent failures to obtain deformation results caused by overly large phase unwrapping errors. 


\section{Data Availability}

The data used to support the findings of this study have not been made available because the research data are classified.

\section{Conflicts of Interest}

The authors declare that they have no conflicts of interest.

\section{Acknowledgments}

This study was supported by the Key Research and Development Project of the 13th Five-Year Plan "Key technologies of mutual feed simulation and intelligent monitoring of dam structure and service environment" (2018YFC0407103) and Youth Science Foundation of the National Natural Science Foundation of China "Study of the method of high precision dynamic monitoring of dam surface deformation by GBSAR time-series of mobile subimage set" (41801381).

\section{References}

[1] A. Ferretti, C. Prati, and F. Rocca, "Permanent scatterers in SAR interferometry," in Proceedings of the IEEE International Geoscience and Remote Sensing Symposium, 1999 IGARSS'99, vol. 3, pp. 1528-1530, Hamburg, Germany, June-July 1999.

[2] A. Ferretti, C. Prati, and F. Rocca, "Analysis of permanent scatterers in SAR interferometry," in Proceedings of the IEEE 2000 International Geoscience and Remote Sensing Symposium IGARSS 2000, vol. 2, pp. 761-763, Honolulu, HI, USA, July 2000.

[3] A. Ferreti, C. Prati, and F. Rocca, "Nonlinear subsidence rate estimation using permanent scatterers in differential SAR interferometry," IEEE Transactions on Geoscience and Remote Sensing, vol. 38, no. 5, pp. 2202-2212, 2000.

[4] A. Ferretti, C. Prati, and F. Rocca, "Permanent scatterers in SAR interferometry," IEEE Transactions on Geoscience and Remote Sensing, vol. 39, no. 1, pp. 8-20, 2001.

[5] V. Greif and J. Vlcko, "Application of the PS-InSAR technique for the post-failure landslide deformation monitoring at Lubietova site in central Slovakia," in Landslide Science and Practice, pp. 15-23, Springer, Berlin, Germany, 2013.

[6] P. Frattini, G. B. Crosta, M. Rossini et al., "Activity and kinematic behaviour of deep-seated landslides from PS-InSAR displacement rate measurements," in Landslides, pp. 1-18, Springer, Berlin, Germany, 2018.

[7] N. Devanthéry, M. Crosetto, M. Cuevas-González, O. Monserrat, A. Barra, and B. Crippa, "Deformation monitoring using persistent scatterer interferometry and sentinel1 SAR data," Procedia Computer Science, vol. 100, pp. 11211126, 2016.

[8] P. Berardino, G. Fornaro, R. Lanari, and E. Sansosti, "A new algorithm for surface deformation monitoring based on small baseline differential SAR interferograms," IEEE Transactions on Geoscience and Remote Sensing, vol. 40, no. 11, pp. 2375-2383, 2002.

[9] O. Mora, J. J. Mallorqui, and A. Broquetas, "Linear and nonlinear terrain deformation maps from a reduced set of interferometric SAR images," IEEE Transactions on Geoscience and Remote Sensing, vol. 41, no. 10, pp. 2243-2253, 2003.

[10] R. Lanari, Ó Mora Sacristan, M. Manunta et al., "A small baseline DIFSAR approach for investigating deformations on full resolution SAR interferograms," IEEE Transactions on Geoscience and Remote Sensing, vol. 47, no. 7, pp. 1377-1386, 2004.

[11] A. Hooper, H. Zebker, P. Segall et al., "A new method for measuring deformation on volcanoes and other natural terrains using InSAR persistent scatterers," Geophysical Research Letters, vol. 31, no. 23, 2004.

[12] N. Adam, B. Kampes, M. Eineder, J. Worawattanamateekul, and M. Kircher, "The development of a scientific permanent scatterer system," in ISPRS Workshop High Resolution Mapping from Space, p. 6, Hannover, Germany, October 2003.

[13] U. Wegmuller, D. Walter, V. Spreckels, and C. L. Werner, "Nonuniform ground motion monitoring with TerraSAR-X persistent scatterer interferometry," IEEE Transactions on Geoscience and Remote Sensing, vol. 48, no. 2, pp. 895-904, 2010.

[14] D. Tarchi, N. Casagli, R. Fanti et al., "Landslide monitoring by using ground-based SAR interferometry: an example of application to the Tessina landslide in Italy," Engineering Geology, vol. 68, no. 1-2, pp. 15-30, 2003.

[15] M. Pieraccini, G. Luzi, D. Mecatti et al., "Ground-based SAR for short and long term monitoring of unstable slopes," in Proceedings of the IEEE 3rd European Radar Conference, EuRAD 2006, pp. 92-95, Manchester, UK, September 2006.

[16] X. Zuo, H. Yu, C. Zi, and X. Xu, "The atmospheric disturbance correction model in slope deformation monitoring using IBIS-L system," Cluster Computing, vol. 19, no. 4, pp. 21572167, 2016.

[17] Z. Qiu, Y. Ma, and X. Guo, "Atmospheric phase screen correction in ground-based SAR with PS technique," SpringerPlus, vol. 5, no. 1, p. 1594, 2016.

[18] Q. Huang, G. Luzi, O. Monserrat et al., "Ground-based synthetic aperture radar interferometry for deformation monitoring: a case study at Geheyan Dam, China," Journal of Applied Remote Sensing, vol. 11, no. 3, p. 036030, 2017.

[19] C. Xing, J. J. Huang, and X. Q. Han, "Research on the environmental effects of GB-SAR for dam monitoring," in Advanced Materials Research, vol. 919-921, pp. 392-397, Trans Tech Publications Inc, Zürich, Switzerland, 2014.

[20] L. Noferini, M. Pieraccini, D. Mecatti et al., "Permanent scatterers analysis for atmospheric correction in groundbased SAR interferometry," IEEE Transactions on Geoscience and Remote Sensing, vol. 43, no. 7, pp. 1459-1471, 2005.

[21] D. Tarchi, G. Antonello, N. Casagli et al., "On the use of ground-based SAR interferometry for slope failure early warning: the Cortenova rock slide (Italy)," in Landslides, pp. 337-342, Springer, Berlin, Germany, 2005.

[22] G. Antonello, N. Casagli, P. Farina et al., "Ground-based SAR interferometry for monitoring mass movements," Landslides, vol. 1, no. 1, pp. 21-28, 2004.

[23] D. Tarchi, N. Casagli, S. Moretti et al., "Monitoring landslide displacements by using ground-based synthetic aperture radar interferometry: application to the Ruinon landslide in the Italian Alps," Journal of Geophysical Research: Solid Earth, vol. 108, no. B8, 2003.

[24] G. Luzi, M. Pieraccini, D. Mecatti et al., "Advances in groundbased microwave interferometry for landslide survey: a case study," International Journal of Remote Sensing, vol. 27, no. 12, pp. 2331-2350, 2006.

[25] G. Herrera, J. A. Fernández-Merodo, J. Mulas et al., “A landslide forecasting model using ground based SAR data: the Portalet case study," Engineering Geology, vol. 105, no. 3-4, pp. 220-230, 2009. 
[26] G. Barla, F. Antolini, M. Barla et al., "Monitoring of the Beauregard landslide (Aosta Valley, Italy) using advanced and conventional techniques," Engineering Geology, vol. 116, no. 3-4, pp. 218-235, 2010.

[27] W. H. Schulz, J. A. Coe, B. L. Shurtleff et al., "Kinematics of the Slumgullion landslide revealed by ground-based InSAR surveys," in Proceedings of the Landslides and Engineered Slopes: Protecting Society Through Improved Understanding-The 11th International and 2nd North American Symposium on Landslides and Engineered Slopes, pp. 3-8, Banff, Canada, June 2012.

[28] N. Casagli, F. Catani, C. Del Ventisette, and G. Luzi, "Monitoring, prediction, and early warning using groundbased radar interferometry," Landslides, vol. 7, no. 3, pp. 291-301, 2010.

[29] N. Casagli, G. Luzi, and C. Del Ventisette, "Monitoring deformations of the Sciara del Fuoco (Stromboli) through ground-based radar interferometry," Acta Vulcanologica, vol. 22, no. 1-2, pp. 77-84, 2010.

[30] F. Bozzano, I. Cipriani, P. Mazzanti, and A. Prestininzi, "Displacement patterns of a landslide affected by human activities: insights from ground-based InSAR monitoring," Natural Hazards, vol. 59, no. 3, pp. 1377-1396, 2011.

[31] E. Intrieri, F. Di Traglia, C. Del Ventisette et al., "Flank instability of stromboli volcano (Aeolian Islands, southern Italy): integration of GB-InSAR and geomorphological observations," Geomorphology, vol. 201, pp. 60-69, 2013.

[32] M. Alba, G. Bernardini, A. Giussani et al., "Measurement of dam deformations by terrestrial interferometric techniques," The International Archives of the Photogrammetry, Remote Sensing and Spatial Information Sciences, vol. 37, no. 1374, pp. 133-139, 2008.

[33] G. Luzi, M. Crosetto, and O. Monserrat, "Advanced techniques for dam monitoring," in Proceedings of the II International Congress on Dam Maintenance and Rehabilitation, pp. 23-25, Zaragoza, Spain, November 2010.

[34] D. Tarchi, H. Rudolf, G. Luzi et al., "SAR interferometry for structural changes detection: a demonstration test on a dam," in Proceedings of the IEEE International Geoscience and Remote Sensing Symposium, IGARSS'99, vol. 3, pp. 1522-1524, Hamburg, Germany, June-July 1999.

[35] A. Corsini, M. Berti, A. Monni et al., "Rapid assessment of landslide activity in Emilia Romagna using GB-InSAR short surveys," in Landslide Science and Practice, pp. 391-399, Berlin, Germany, 2013.

[36] O. Monserrat, M. Crosetto, and G. Luzi, "A review of groundbased SAR interferometry for deformation measurement," ISPRS Journal of Photogrammetry and Remote Sensing, vol. 93, pp. 40-48, 2014.

[37] M. Lazecký, D. Perissin, W. Zhiying, L. Ling, and Q. Yuxiao, "Observing dam's movements with spaceborne SAR interferometry," in Engineering Geology for Society and Territory-Volume 5, pp. 131-136, Springer, Cham, Switzerland, 2015.

[38] M. Crosetto, O. Monserrat, G. Luzi, M. Cuevas, and N. Devanthéry, "Deformation monitoring using groundbased SAR data," in Engineering Geology for Society and Territory-Volume 5, pp. 137-140, Springer, Cham, Switzerland, 2015.

[39] P. Mazzanti, A. Brunetti, and A. Bretschneider, "A new approach based on terrestrial remote-sensing techniques for rock fall hazard assessment," in Modern Technologies for Landslide Monitoring and Prediction, pp. 69-87, Springer, Berlin, Germany, 2015.
[40] K. A. Lukin, A. A. Mogyla, V. P. Palamarchuk et al., "Monitoring of St. Sophia Cathedral interior using Ka-band ground based noise waveform SAR," in Proceedings of the 2009 European Radar Conference (EuRAD), pp. 215-217, Rome, Italy, September-October 2009.

[41] K. A. Lukin, A. A. Mogyla, P. L. Vyplavin et al., "Monitoring of Kiev St. Sophia Cathedral using Ka-band ground based noise SAR," in Proceedings of the International Radar Symposium 2009, pp. 09-11, Hamburg, Germany, December 2009.

[42] M. Pieraccini, G. Luzi, D. Mecatti et al., "Remote sensing of building structural displacements using a microwave interferometer with imaging capability," NDT \& E International, vol. 37, no. 7, pp. 545-550, 2004.

[43] D. Tapete, N. Casagli, G. Luzi, R. Fanti, G. Gigli, and D. Leva, "Integrating radar and laser-based remote sensing techniques for monitoring structural deformation of archaeological monuments," Journal of Archaeological Science, vol. 40, no. 1, pp. 176-189, 2013.

[44] L. Pipia, X. Fabregas, A. Aguasca, and C. Lopez-Martinez, "Polarimetric temporal analysis of urban environments with a ground-based SAR," IEEE Transactions on Geoscience and Remote Sensing, vol. 51, no. 4, pp. 2343-2360, 2013.

[45] S. Long, T. Li, and T. Feng, "Study on selection of PS point targets," Journal of Geodesy and Geodynamics, vol. 31, no. 4, pp. 144-148, 2011.

[46] L. Guoxiang, C. Qiang, L. Xiaojun et al., Theory and Method of Permanent Scatterer Radar Interference, Science Press, Beijing, China, 2012.

[47] T. Zeng, T. Zhang, W. Tian, and C. Hu, "A novel subsidence monitoring technique based on space-surface bistatic differential interferometry using GNSS as transmitters," Science China Information Sciences, vol. 58, no. 6, pp. 1-16, 2015.

[48] C. Hu, M. Zhu, T. Zeng et al., "High-precision deformation monitoring algorithm for GBSAR system: rail determination phase error compensation," Science China Information Sciences, vol. 59, no. 8, p. 82307, 2016.

[49] R. Caduff, F. Schlunegger, A. Kos, and A. Wiesmann, "A review of terrestrial radar interferometry for measuring surface change in the geosciences," Earth Surface Processes and Landforms, vol. 40, no. 2, pp. 208-228, 2015.

[50] K. A. Lukin, A. A. Mogyla, and P. L. Vyplavin, "Ground-based noise waveform SAR and differential interferometry for remote monitoring of large objects," in Proceedings of the MSMW'07 Symposium Proceedings, pp. 445-447, Kharkov, Ukraine, June 2007.

[51] K. A. Lukin, P. L. Vyplavin, V. P. Palamarchuk, V. V. Kudriashov, K. Kulpa, and J. Kulpa, "Precision of target shifts detection using Ka-band ground based noise waveform SAR," in Proceedings of the 3rd International Conference on Noise Radar Technology, NRT-2012, Yalta, Ukraine, September 2012.

[52] M. Crosetto, O. Monserrat, M. Cuevas-González, N. Devanthéry, and B. Crippa, "Persistent scatterer interferometry: a review," ISPRS Journal of Photogrammetry and Remote Sensing, vol. 115, pp. 78-89, 2016. 


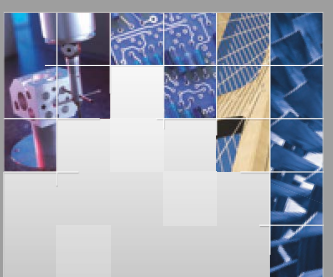

\section{Enfincering}
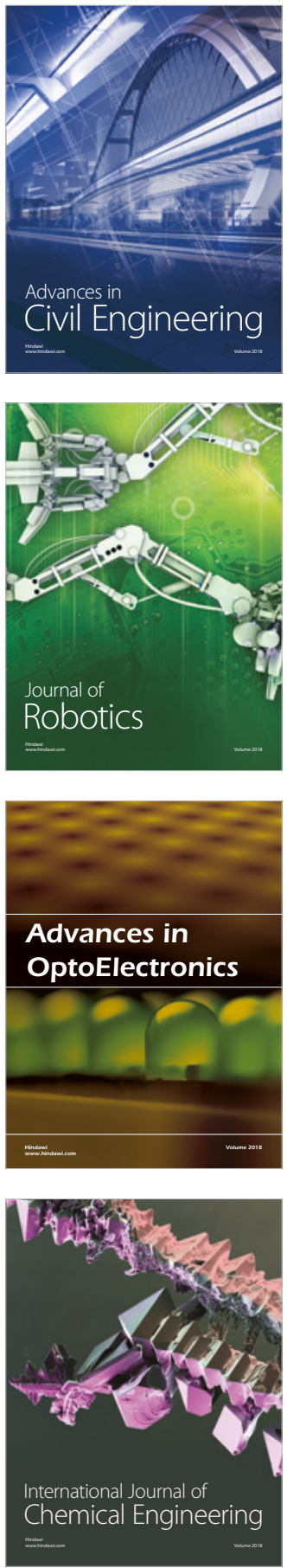

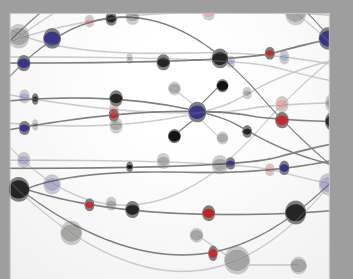

\section{Rotating \\ Machinery}

The Scientific World Journal

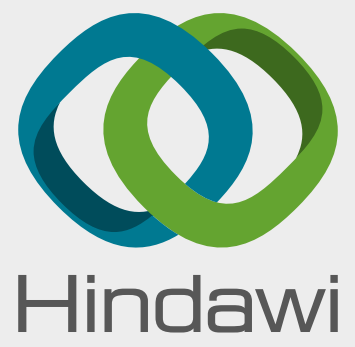

Submit your manuscripts at

www.hindawi.com
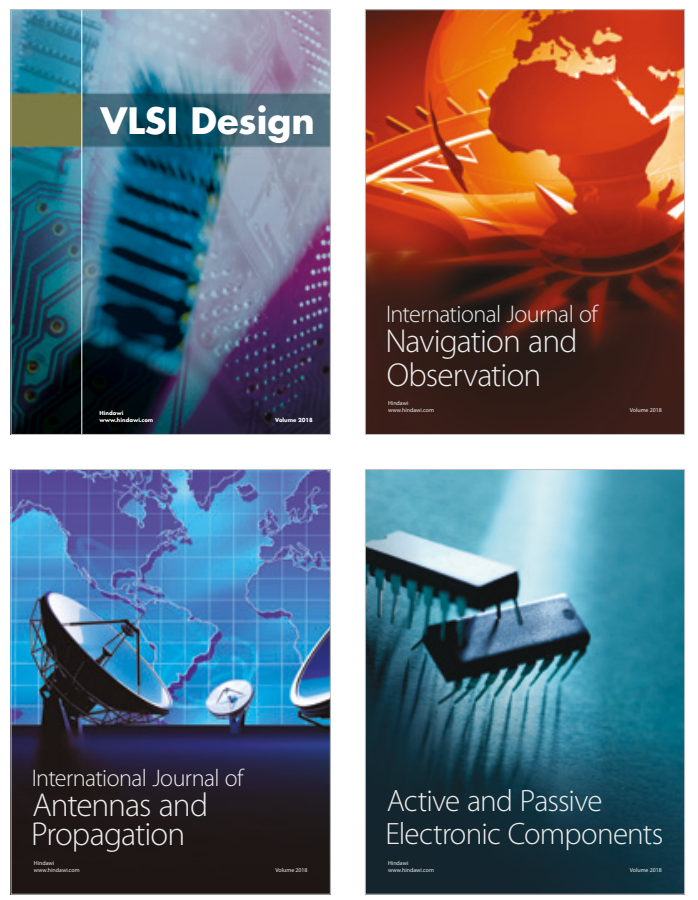
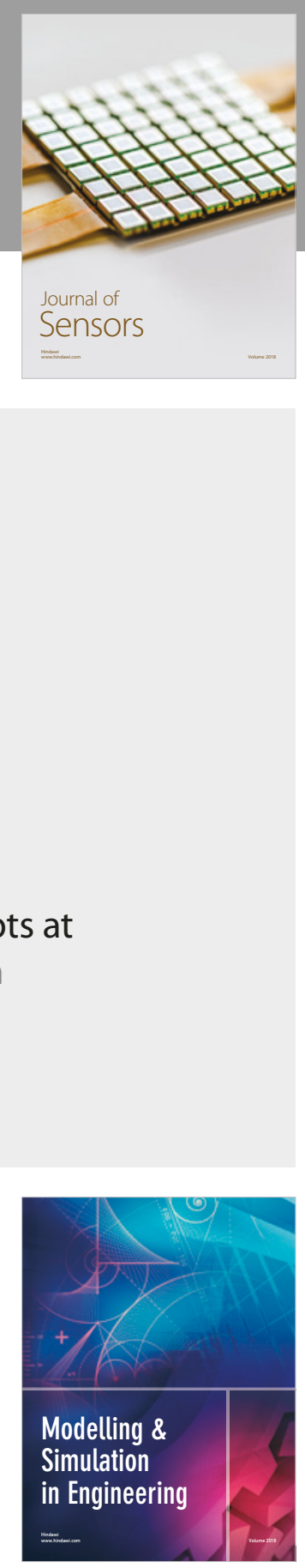

\section{Advances \\ Multimedia}
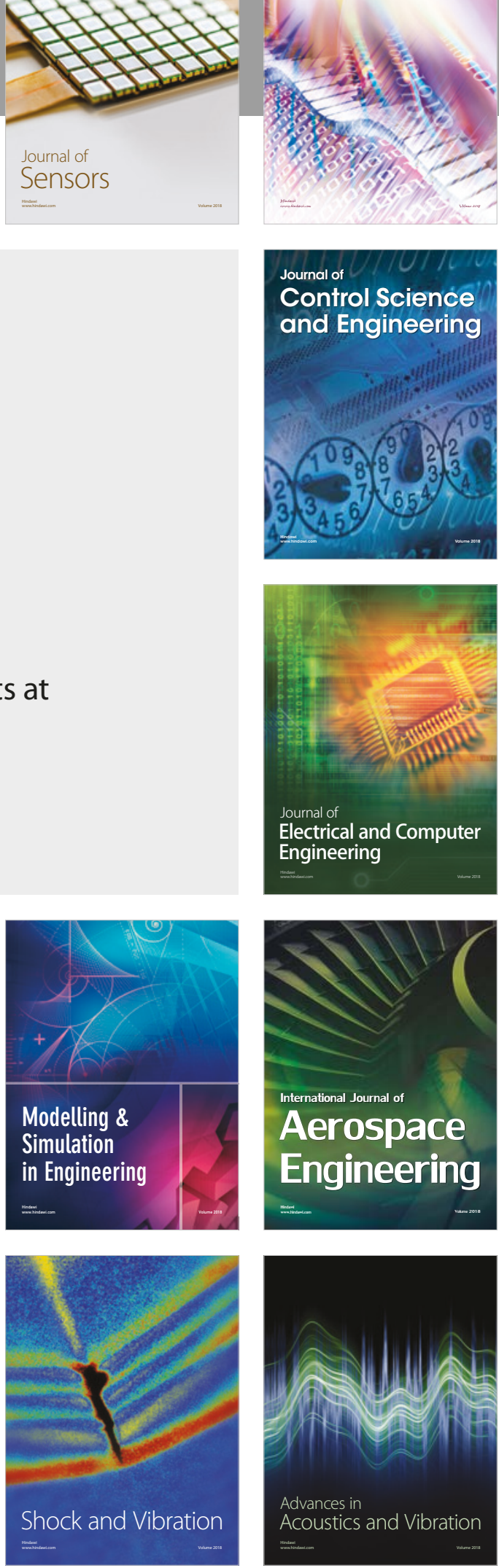